\title{
Early parasite clearance following artemisinin- based combination therapy among Ugandan children with uncomplicated Plasmodium falciparum malaria
}

Mary K Muhindo ${ }^{1 *}$, Abel Kakuru ${ }^{1}$, Prasanna Jagannathan ${ }^{2}$, Ambrose Talisuna ${ }^{1,3}$, Emmanuel Osilo ${ }^{1}$, Francis Orukan ${ }^{1}$, Emmanuel Arinaitwe ${ }^{1}$, Jordan W Tappero ${ }^{4}$, Frank Kaharuza ${ }^{5}$, Moses R Kamya ${ }^{6}$ and Grant Dorsey ${ }^{2}$

\begin{abstract}
Background: Artemisinin-based combination therapy (ACT) is widely recommended as first-line therapy for uncomplicated Plasmodium falciparum malaria worldwide. Artemisinin resistance has now been reported in Southeast Asia with a clinical phenotype manifested by slow parasite clearance. Although there are no reliable reports of artemisinin resistance in Africa, there is a need to better understand the dynamics of parasite clearance in African children treated with ACT in order to better detect the emergence of artemisinin resistance.

Methods: Data from a cohort of Ugandan children four to five years old, enrolled in a longitudinal, randomized, clinical trial comparing two leading ACT, artemether-lumefantrine (AL) and dihydroartemisinin-piperaquine (DP), were analysed. For all episodes of uncomplicated P. falciparum malaria over a 14-month period, daily blood smears were performed for three days following the initiation of therapy. Associations between pre-treatment variables of interest and persistent parasitaemia were estimated using multivariate, generalized, estimating equations with adjustment for repeated measures in the same patient.
\end{abstract}

Results: A total of 202 children were included, resulting in 416 episodes of malaria treated with AL and 354 episodes treated with DP. The prevalence of parasitaemia on days 1, 2, and 3 following initiation of therapy was 67.6, 5.6 and $0 \%$ in those treated with $\mathrm{AL}$, and $52.2,5.7$ and $0.3 \%$ in those treated with DP. Independent risk factors for persistent parasitaemia on day 1 included treatment with $A L$ vs DP (RR $=1.34,95 \% \mathrm{Cl} 1.20-1.50, p<0.001$ ), having a temperature $\geq 38.0^{\circ} \mathrm{C}$ vs $<37.0^{\circ} \mathrm{C}(\mathrm{RR}=1.19,95 \% \mathrm{Cl} 1.05-1.35, \mathrm{p}=0.007)$ and having a parasite density $>20,000 / \mu \mathrm{L}$ vs $<4,000 / \mu \mathrm{L}(\mathrm{RR}=3.37,95 \% \mathrm{Cl} 2.44-4.49, \mathrm{p}<0.001)$. Independent risk factors for having persistent parasitaemia on day 2 included elevated temperature, higher parasite density, and being HIV infected.

Conclusions: Among Ugandan children, parasite clearance following treatment with AL or DP was excellent with only one of 752 patients tested having a positive blood slide three days after initiation of therapy. The type of ACT given, pre-treatment temperature, pre-treatment parasite density and HIV status were associated with differences in persistent parasitaemia, one or two days following therapy.

Trial registration: Current Controlled Trials Identifier NCT00527800.

Keywords: Malaria, Plasmodium falciparum, Artemisinin-based combination therapy, Parasite clearance, Artemether-lumefantrine, Dihydroartemisin-piperaquine

\footnotetext{
* Correspondence: marymkakuru@gmail.com

${ }^{1}$ Infectious Diseases Research Collaboration, Mulago Hospital Campus,

PO Box 7475, Kampala, Uganda

Full list of author information is available at the end of the article
} 


\section{Background}

Artemisinin-based combination therapy (ACT) is currently recommended for the treatment of uncomplicated Plasmodium falciparum malaria by the World Health Organization and has been adopted as first-line therapy in most malaria-endemic countries [1]. Marked reductions in malaria-associated morbidity and mortality in many parts of the world have been attributed to the replacement of failing monotherapies with highly effective ACT and the scale-up of vector control measures [2]. However the recent emergence and/or spread of artemisinin resistance in parts of Southeast Asia [3-6] poses a serious threat to malaria control efforts. Although artemisinin resistance has not yet been reported in Africa, there is a historical precedence of resistance to older monotherapies emerging in Asia and spreading to Africa with devastating effects [7-9]. Thus early and accurate detection of artemisinin resistance in African populations will be critical for the implementation of containment efforts.

The phenotype of artemisinin resistance is characterized by a significant delay in parasite clearance following initiation of therapy [3-6]. As there are no reliable molecular markers of resistance and in vitro correlates have been inconsistent [10], surveillance of artemisinin resistance to date has relied on in vivo studies to measure early clearance of peripheral parasitaemia by microscopy. The use of sampling multiple times a day at measured time points to estimate the rate of parasite clearance has been proposed as an accurate and reliable method for the early detection of artemisinin resistance [11]. However, this approach may be difficult to implement in settings of routine in vivo drug efficacy studies among outpatients. An alternative approach is to measure the proportion of patients with detectable parasitaemia one, two or three days after the initiation of therapy $[12,13]$. Although this alternative approach is simple to implement, there are multiple factors that could be associated with parasite clearance independent of artemisinin resistance, which may confound the interpretation of results.

In this study the proportion of patients with detectable parasitaemia one, two and three days after initiation of therapy were measured in a cohort of Ugandan children randomized to two different ACT regimens. The objective of the study was to identify factors associated with early parasite clearance in a setting where artemisinin resistance has not yet occurred. This information will be important for the interpretation of future surveillance studies aimed at identifying early signs of artemisinin resistance in African populations.

\section{Methods}

\section{Study design, site and population}

This study was part of a larger open-label, randomized trial conducted at Tororo, an area in Eastern Uganda with high malaria transmission intensity [14]. The methods of the main study have been described previously $[15,16]$. Briefly, convenience sampling was used to enrol a cohort of HIV infected and uninfected children referred to a dedicated study clinic from an adjacent post-natal clinic at Tororo District Hospital. Eligibility criteria included: 1) age six weeks to 12 months, 2) documented HIV status of mother and child, 3) agreement to come to the study clinic for any febrile episode or other illness, 4) residence within a $30-\mathrm{km}$ radius of the study clinic, 5) absence of active medical problem requiring inpatient evaluation at the time of screening, and, 6) provision of informed consent. At enrolment, all study participants received a long-lasting, insecticide-treated bed net (ITN).

\section{Follow-up of study participants}

Subjects were followed for all of their medical problems at a dedicated study clinic open seven days a week and parents/guardians were encouraged to bring their children to the study clinic whenever they were ill. HIVinfected children were prescribed daily trimethoprimsulphamethoxazole (TS) prophylaxis. Medications with anti-malarial activity were avoided for the treatment of non-malarial illnesses. Study participants were followed until they reached five years of age or met one of the following criteria for early study withdrawal: 1) movement out of the study area, 2) inability to be located for $>60$ consecutive days, 3) withdrawal of informed consent, 4) inability to adhere to the study schedule and procedures, or, 5) inability to tolerate the drugs used for malaria treatment.

\section{Malaria diagnosis and treatment}

Children who presented to the study clinic with a documented fever (tympanic temperature $\geq 38.0^{\circ} \mathrm{C}$ ) or history of fever in the previous 24 hours had blood obtained by finger prick for a thick smear. If the thick smear was positive, the patient was diagnosed with malaria regardless of parasite density. Children who were aged $\geq$ four months and weighing $\geq 5 \mathrm{~kg}$ were randomized to receive either artemetherlumefantrine (AL) or dihydroartemisinin-piperaquine (DP) at the time they got their first episode of uncomplicated malaria. Study participants received the same treatment regimen for all subsequent episodes of uncomplicated malaria. Study drugs were given according to weightbased guidelines for fractions of tablets as follows: $\mathrm{AL}$ (tablets of $20 \mathrm{mg}$ of artemether and $120 \mathrm{mg}$ of lumefantrine; Coartem; Novartis), administered as one (5-14 kg) or two (15-24 kg) tablets given twice daily for three days; and DP (tablets of $40 \mathrm{mg}$ of dihydroartemisinin and 320 mg of piperaquine; Duocotecxin; Holley Pharm), targeting a total dose of 6.4 and $51.2 \mathrm{mg} / \mathrm{kg}$ of dihydroartemisinin and piperaquine, respectively, given in three equally divided daily doses to the nearest one-quarter 
tablet. Study drugs were crushed, mixed with water and administered to the patient. Patients were given a glass of milk after each dose. The first daily dose of study drugs was directly observed at the study clinic. After each dose, children were observed for 30 minutes, and the dose was re-administered if vomiting occurred. For children treated with $\mathrm{AL}$, the second daily dose was packaged and the parent or guardian was given verbal instructions for proper administration of the medication at home with clear emphasis on when the evening dose should be given. Episodes of complicated malaria and treatment failures occurring within 14 days of initiating treatment were treated with quinine. All children with malaria were followed up on days $1,2,3,7,14,21$, and 28 following enrolment.

\section{Laboratory methods}

Thick and thin blood smears were stained with $2 \%$ Giemsa for 30 minutes and read by trained laboratory technologists who were not involved in direct patient care. Parasite densities were calculated from thick blood smears by counting the number of asexual parasites per 200 leukocytes (or per 500 leukocytes, if the count was $<10$ asexual parasites/200 leukocytes), assuming a leukocyte count of $8,000 / \mu \mathrm{l}$. A blood smear was considered negative when the examination of 100 high power fields did not reveal asexual parasites. For quality control, all slides were read by a second reader. An independent third reader settled any discrepancies between the first and second readings. Laboratory technicians were blinded to the study participants' treatment assignments. Thin smears were used to determine the parasite species.

\section{Statistical methods}

Data were double entered into an Access database and analysed using Stata version 11 (Stata Corp, College Station, TX, USA). This study included only data from episodes of uncomplicated $P$. falciparum malaria diagnosed between October 2011 and December 2012 when routine blood smears were added on day 1 of malaria follow-up. During this period, all children remaining in the cohort study were between 47 and 60 months of age. The primary outcome of interest was the proportion of patients who remained parasitaemic by microscopy one, two and three days following initiation of therapy. Secondary outcomes included persistence of fever (either subjective fever in the previous 24 hours or tympanic temperature $\geq 38.0^{\circ} \mathrm{C}$,) during the first three days following initiation of therapy and 28-day standardized WHO treatment outcomes unadjusted by genotyping. The treatment outcomes were classified as: adequate clinical and parasitological response (all blood smears negative after day 3); early treatment failure (presence of danger signs or complicated malaria with a positive blood smear within three days of treatment, or day 2 parasite density > day 0 parasite density, or day 3 parasite density $>25 \%$ of day 0 parasite density, or positive blood smear on day 3 with a tympanic temperature $\geq 38.0^{\circ} \mathrm{C}$ ); late clinical failure (first positive blood smear after day 3 in the presence of fever); and late parasitological failure (first positive blood smear after day 3 in the absence of fever). Risk factors of interest included the ACT regimen (AL vs DP); $\mathrm{mg} / \mathrm{kg}$ dosing of anti-malarials; treatment episode number; pretreatment temperature, parasite density and haemoglobin; age; gender; and HIV status. We explored the relationship between pre-treatment parasite density and proportion with parasitaemia and it was nonlinear. We thus created a categorical variable for parasite density to create the most parsimonious model that best fit the distribution of the data. Associations between risk factors of interest and early persistent parasitaemia were estimated using generalized estimating equations with robust standard errors and adjustment for repeated measures in the same patient. Risk factors associated with the outcome of interest with a p-value of $<0.05$ in univariate analyses were included in the final multivariate model, with the exception of age and gender which were also included.

\section{Ethical approval}

Informed consent was obtained from the parents or legal guardian of all study participants. The study protocol was approved by the Uganda National Council of Science and Technology and the institutional review boards of the University of California, San Francisco, Makerere University, the University of Washington, and the Centers for Disease Control and Prevention.

\section{Results}

\section{Study profile and characteristics of the malaria episodes}

A total of 787 episodes of malaria were treated in 202 study participants during the study period of October 2011 to December 2012. Three episodes of complicated malaria treated with quinine and 14 episodes of malaria caused by non-falciparum species were excluded from the analysis (Figure 1). Of 770 uncomplicated malaria episodes due to $P$. falciparum, 416 episodes were treated with $\mathrm{AL}$ and 354 episodes were treated with DP. The mean age, temperature, and haemoglobin level was similar in both treatment arms (Table 1). Episodes treated with DP had a higher parasite density compared to those treated with $\mathrm{AL}$ $(20,295$ vs 13,258 parasites $/ \mu \mathrm{l}, \mathrm{p}=0.004)$. A total of 38 (4.9\%) episodes occurred in HIV-infected children and were equally distributed between the two treatment arms.

\section{Malaria treatment outcomes}

On day one following initiation of anti-malarial treatment, a total of 450 of $745(60.4 \%)$ episodes with blood smears done had persistent asexual parasitaemia by microscopy 


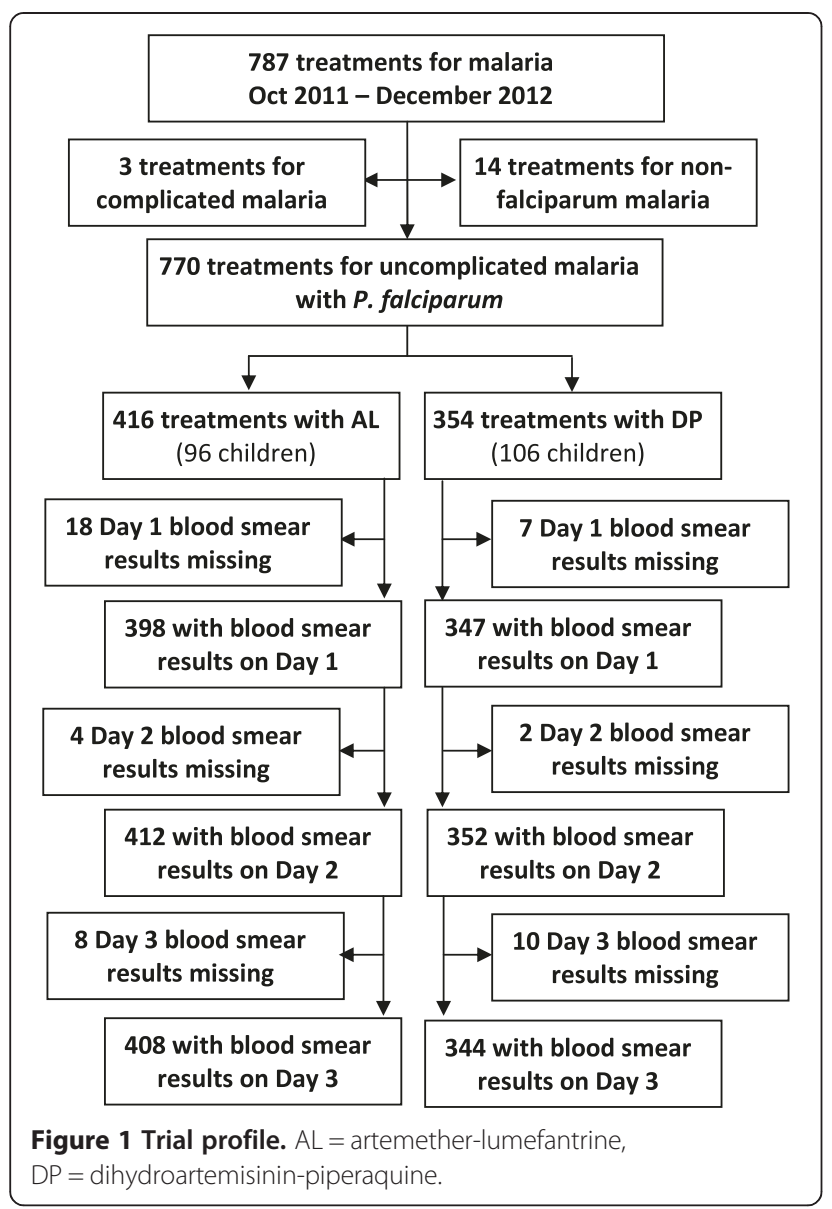

Table 1 Baseline characteristics of all episodes of uncomplicated falciparum malaria

\begin{tabular}{lll}
\hline Characteristic & Treatment arm & \\
\cline { 2 - 3 } & AL (n=416) & DP (n=354) \\
\hline $\begin{array}{l}\text { Patient age in months, } \\
\text { mean (range) }\end{array}$ & $56(48-60)$ & $56(47-60)$ \\
Gender, number female (\%) & $210(50.5)$ & $141(39.8)$ \\
$\begin{array}{l}\text { Dosing of artemisinin drug } \\
\text { in mg/kg, median (range) }\end{array}$ & $14.3(8.3-16.6)$ & $7.2(5.8-8.5)$ \\
$\begin{array}{l}\text { Dosing of partner drug in } \\
\text { mg/kg, median (range) }\end{array}$ & $85.7(50.0-99.3)$ & $57.5(46.2-67.9)$ \\
Temperature ${ }^{\circ} \mathrm{C}$, mean (SD) & $37.6(1.0)$ & $37.7(1.0)$ \\
$\begin{array}{l}\text { Parasite density per } \mu \mathrm{L}, \\
\text { geometric mean }\end{array}$ & 13,258 & 20,295 \\
Haemoglobin g/dL, & $11.1(1.5)$ & $11.2(1.5)$ \\
mean (SD) & & $20(5.7 \%)$ \\
HIV infected, $n$ (\%) & $18(4.3 \%)$ & $2(1-13)$ \\
Treatments per child, median (range) & $3(1-13)$ & \\
\hline
\end{tabular}

and the prevalence was higher in those treated with $\mathrm{AL}$ compared to DP (67.6 vs 52.2\%, $p<0.001)$. On day two following initiation of anti-malarial treatment, a total of 43 of 764 (5.6\%) episodes with blood smears done had persistent asexual parasitaemia by microscopy and the prevalence was similar between the two ACT treatment arms. On day three following initiation of anti-malarial treatment, only one of $752(0.1 \%)$ episodes with blood smears done had persistent parasitaemia (Table 2). This patient was treated with DP and had a parasite density of only 16 asexual parasites $/ \mu \mathrm{L}$ on day three which cleared by day seven when the next blood smear was done.

Patients treated with AL were more likely to be febrile on day 1 following initiation of anti-malarial treatment compared to those treated with DP (30 vs $18.4 \%$, respectively, $P=0.002$ ). There was no significant difference between the two ACT treatment arms in the prevalence of fever on day two and three following initiation of antimalarial therapy (Table 2). Considering 28-day WHO treatment outcomes, there was only one early treatment failure, which occurred in a patient treated with DP due to an increase in the parasite density from 12,720 asexual parasites $/ \mu \mathrm{L}$ on day 0 to 18,960 asexual parasites/ $\mu \mathrm{L}$ on day two. Interestingly, when this patient returned to clinic on day three the blood smear was negative and therefore rescue therapy was not given. Patients treated with DP were significantly more likely to have an adequate clinical and parasitological response compared to those treated with AL (87.9 vs 45.4\%, $\mathrm{p}<0.001)$ (Table 2).

Table 2 Response to anti-malarial therapy

\begin{tabular}{|c|c|c|c|}
\hline \multirow[t]{2}{*}{ Characteristic } & \multicolumn{2}{|c|}{ Treatment arm } & \multirow[t]{2}{*}{ p-value } \\
\hline & $\mathrm{AL}(\mathrm{n}=416)$ & $D P(n=354)$ & \\
\hline \multicolumn{4}{|l|}{ Parasite persistence, $\mathrm{n}(\%)$} \\
\hline Positive blood smear day 1 & $269(67.6 \%)$ & $181(52.2 \%)$ & $<0.001$ \\
\hline Positive blood smear day 2 & $23(5.6 \%)$ & $20(5.7 \%)$ & 0.92 \\
\hline Positive blood smear day 3 & 0 & $1(0.3 \%)$ & $\mathrm{N} / \mathrm{A}$ \\
\hline \multicolumn{4}{|l|}{ Fever persistence, n (\%) } \\
\hline Febrile* day 1 & $124(30.0 \%)$ & $65(18.4 \%)$ & 0.002 \\
\hline Febrile* day 2 & $8(1.9 \%)$ & $11(3.1 \%)$ & 0.28 \\
\hline Febrile* day 3 & $7(1.7 \%)$ & $7(2.0 \%)$ & 0.78 \\
\hline \multicolumn{4}{|l|}{$\begin{array}{l}\text { 28-day WHO treatment } \\
\text { outcome, } n(\%)\end{array}$} \\
\hline Lost to follow-up & $16(3.9 \%)$ & $13(3.7 \%)$ & \\
\hline Early treatment failure & 0 & $1(0.3 \%)$ & \\
\hline Late parasitological failure & 137 (32.9\%) & $22(6.2 \%)$ & $<0.001$ \\
\hline Late clinical failure & $74(17.8 \%)$ & $7(2.0 \%)$ & \\
\hline $\begin{array}{l}\text { Adequate clinical and } \\
\text { parasitological response }\end{array}$ & $189(45.4 \%)$ & $311(87.9 \%)$ & \\
\hline
\end{tabular}

*Subjective fever in the previous 24 hours or temperature $\geq 38.0^{\circ} \mathrm{C}$ (tympanic). 
Risk factors associated with a persistent parasitaemia on days one and two following initiation of anti-malarial therapy

In univariate analyses, the anti-malarial treatment regimen administered, pre-treatment temperature, and pretreatment parasite density were significantly associated with persistent parasitaemia on day one following initiation of anti-malarial therapy. In the final multivariate model the following factors were significantly associated with an increased risk of persistent parasitaemia on day one: treatment with AL compared to $\mathrm{DP}$ ( $\mathrm{RR}=1.34,95 \%$ CI 1.20-1.50, $\mathrm{p}<0.001)$; pre-treatment temperature $\geq 38.0$ compared to $<37.0(\mathrm{RR}=1.19,95 \% \mathrm{CI} 1.05-1.35, \mathrm{p}=0.007)$; and pre-treatment parasite density $>20,000 / \mu \mathrm{L}(\mathrm{RR}=3.31$, 95\% CI 2.44-4.49, $\mathrm{p}<0.001)$ and $4,000-20,000 / \mu \mathrm{L}(\mathrm{RR}=$ 2.61, 95\% CI 1.89-3.59, $\mathrm{p}<0.001)$ compared to $<4,000 / \mu \mathrm{L}$ (Table 3). In univariate analyses pre-treatment temperature, pre-treatment parasite density, and HIV status were significantly associated with persistent parasitaemia on day two following initiation of anti-malarial therapy. In the final multivariate model the following factors were significantly associated with an increased risk of persistent parasitaemia on day two: pre-treatment temperature $\geq 37.0$ $(\mathrm{RR}=2.32,95 \%$ CI 1.00-5.38, $\mathrm{p}=0.049)$; pre-treatment parasite density $>20,000 / \mu \mathrm{L}(\mathrm{RR}=5.09,95 \%$ CI $2.19-11.9$, $\mathrm{p}<0.001)$; and being HIV infected $(\mathrm{RR}=3.93,95 \% \mathrm{CI}$ 1.74-8.88, $\mathrm{p}=0.001$ ) (Table 4).

\section{Discussion}

In this study of 770 episodes of uncomplicated falciparum malaria in Ugandan children randomized to therapy with AL or DP, parasite clearance was excellent with only one episode of parasitaemia documented by microscopy three days after initiation of therapy. To better understand the dynamics of early parasite clearance following ACT treatment in an African setting without evidence of artemisinin resistance, several risk factors associated with persistent parasitaemia one and two days after initiation of therapy were identified. Considering persistent parasitaemia on day one, treatment with AL compared to DP, an elevated pre-treatment temperature, and higher pretreatment parasite density, were independently associated with a significantly increased risk of persistent parasitaemia. Considering persistent parasitaemia on day two, an elevated pre-treatment temperature, higher pre-treatment parasite density and being HIV infected were independently associated with a significantly increased risk of persistent parasitaemia.

The rationale behind ACT is based on the highly potent, but short-acting artemisinin component causing rapid

Table 3 Associations between variables of interest and a positive blood slide on day 1

\begin{tabular}{|c|c|c|c|c|c|c|}
\hline \multirow[t]{2}{*}{ Variable } & \multirow[t]{2}{*}{ Categories } & \multirow{2}{*}{$\begin{array}{l}\text { Risk of positive blood } \\
\text { smear on day } 1\end{array}$} & \multicolumn{2}{|c|}{ Univariate analysis } & \multicolumn{2}{|c|}{ Multivariate analysis } \\
\hline & & & $\mathrm{RR}^{*}(95 \% \mathrm{Cl})$ & p-value & $\mathrm{RR}^{\dagger}(95 \% \mathrm{Cl})$ & p-value \\
\hline \multirow[t]{2}{*}{ Anti-malarial treatment } & $\mathrm{DP}$ & $52.2 \%$ & 1.0 (reference) & - & 1.0 (reference) & - \\
\hline & $\mathrm{AL}$ & $67.6 \%$ & $1.30(1.13-1.49)$ & $<0.001$ & $1.35(1.21-1.50)$ & $<0.001$ \\
\hline \multirow[t]{4}{*}{$\mathrm{mg} / \mathrm{kg}$ dosing of anti-malarial } & $\geq$ median $(\mathrm{DP})$ & $55.0 \%$ & 1.0 (reference) & - & \multirow{4}{*}{\multicolumn{2}{|c|}{ Not included in final model }} \\
\hline & $<$ median (DP) & $49.4 \%$ & $0.96(0.78-1.18)$ & 0.68 & & \\
\hline & $\geq \operatorname{median}(\mathrm{AL})$ & $64.3 \%$ & 1.0 (reference) & - & & \\
\hline & $<$ median $(\mathrm{AL})$ & $70.7 \%$ & $1.11(0.96-1.28)$ & 0.16 & & \\
\hline \multirow[t]{3}{*}{ Temperature ${ }^{\circ} \mathrm{C}$} & $<37.0$ & $48.2 \%$ & 1.0 (reference) & - & 1.0 (reference) & - \\
\hline & $37.0-37.9$ & $59.7 \%$ & $1.22(1.03-1.44)$ & 0.02 & $1.09(0.96-1.24)$ & 0.19 \\
\hline & $\geq 38.0$ & $71.2 \%$ & $1.47(1.25-1.73)$ & $<0.001$ & $1.17(1.04-1.33)$ & 0.01 \\
\hline \multirow[t]{3}{*}{ Parasite density per $\mu \mathrm{L}$} & $<4,000$ & $21.3 \%$ & 1.0 (reference) & - & 1.0 (reference) & - \\
\hline & $4,000-20,000$ & $57.4 \%$ & $2.64(1.93-3.63)$ & $<0.001$ & $2.62(1.90-3.62)$ & $<0.001$ \\
\hline & $>20,000$ & $73.5 \%$ & $3.39(2.51-4.59)$ & $<0.001$ & $3.31(2.44-4.49)$ & $<0.001$ \\
\hline \multirow[t]{2}{*}{ Haemoglobin g/dL } & $\geq 10$ & $60.0 \%$ & 1.0 (reference) & - & \multirow{2}{*}{\multicolumn{2}{|c|}{ Not included in final model }} \\
\hline & $<10$ & $64.0 \%$ & $1.08(0.92-1.26)$ & 0.33 & & \\
\hline \multirow[t]{2}{*}{ HIV status } & Negative & $60.5 \%$ & 1.0 (reference) & - & \multirow{2}{*}{\multicolumn{2}{|c|}{ Not included in final model }} \\
\hline & Positive & $58.3 \%$ & $0.97(0.72-1.31)$ & 0.84 & & \\
\hline \multirow[t]{3}{*}{ Episode number } & $1-2$ & $59.9 \%$ & 1.0 (reference) & & \multirow{3}{*}{\multicolumn{2}{|c|}{ Not included in final model }} \\
\hline & $3-4$ & $57.1 \%$ & $0.94(0.82-1.09)$ & 0.42 & & \\
\hline & $\geq 5$ & $65.0 \%$ & $1.02(0.90-1.17)$ & 0.74 & & \\
\hline
\end{tabular}


Table 4 Associations between variables of interest and a positive blood slide on day 2

\begin{tabular}{|c|c|c|c|c|c|c|}
\hline \multirow[t]{2}{*}{ Variable } & \multirow[t]{2}{*}{ Categories } & \multirow{2}{*}{$\begin{array}{l}\text { Risk of positive blood } \\
\text { smear on day } 2\end{array}$} & \multicolumn{2}{|c|}{ Univariate analysis } & \multicolumn{2}{|c|}{ Multivariate analysis } \\
\hline & & & $\mathrm{RR}^{*}(95 \% \mathrm{Cl})$ & p-value & $\mathrm{RR}^{\dagger}(95 \% \mathrm{Cl})$ & p-value \\
\hline \multirow[t]{2}{*}{ Anti-malarial treatment } & DP & $5.7 \%$ & 1.0 (reference) & - & \multirow{2}{*}{\multicolumn{2}{|c|}{ Not included in final model }} \\
\hline & $\mathrm{AL}$ & $5.6 \%$ & $1.03(0.55-1.95)$ & 0.92 & & \\
\hline \multirow[t]{4}{*}{$\mathrm{mg} / \mathrm{kg}$ dosing of anti-malarial } & $\geq$ median $(\mathrm{DP})$ & $5.8 \%$ & 1.0 (reference) & - & \multicolumn{2}{|c|}{ Not included in final model } \\
\hline & $<$ median (DP) & $5.6 \%$ & $1.00(0.41-2.43)$ & 0.99 & & \\
\hline & $\geq$ median (AL) & $4.0 \%$ & 1.0 (reference) & - & & \\
\hline & $<\operatorname{median}(\mathrm{AL})$ & $7.1 \%$ & $1.74(0.70-4.38)$ & 0.23 & & \\
\hline \multirow[t]{3}{*}{ Temperature ${ }^{\circ} \mathrm{C}$} & $<37.0$ & $2.6 \%$ & 1.0 (reference) & - & 1.0 (reference) & - \\
\hline & $37.0-37.9$ & $5.9 \%$ & $2.35(0.98-5.59)$ & 0.05 & $2.32(1.01-5.31)$ & 0.048 \\
\hline & $\geq 38.0$ & $7.8 \%$ & $3.09(1.28-7.46)$ & 0.01 & & \\
\hline \multirow[t]{3}{*}{ Parasite density per $\mu \mathrm{L}$} & $<4,000$ & $1.4 \%$ & 1.0 (reference) & - & 1.0 (reference) & - \\
\hline & $4,000-20,000$ & $1.3 \%$ & & & & \\
\hline & $>20,000$ & $8.3 \%$ & $5.79(2.35-14.3)$ & $<0.001$ & $5.12(2.12-12.37)$ & $<0.001$ \\
\hline \multirow[t]{2}{*}{ Haemoglobin $\mathrm{g} / \mathrm{dL}$} & $\geq 10$ & $5.4 \%$ & 1.0 (reference) & - & \multirow{2}{*}{\multicolumn{2}{|c|}{ Not included in final model }} \\
\hline & $<10$ & $6.0 \%$ & $1.06(0.46-2.45)$ & 0.89 & & \\
\hline \multirow[t]{2}{*}{ HIV status } & Negative & $5.0 \%$ & 1.0 (reference) & - & 1.0 (reference) & - \\
\hline & Positive & $19.4 \%$ & $3.87(1.85-8.12)$ & $<0.001$ & 3.69 (1.54-8.84) & 0.003 \\
\hline \multirow[t]{3}{*}{ Episode number } & $1-2$ & $6.9 \%$ & 1.0 (reference) & - & \multirow{3}{*}{\multicolumn{2}{|c|}{ Not included in final model }} \\
\hline & $3-4$ & $5.1 \%$ & $0.74(0.37-1.48)$ & 0.39 & & \\
\hline & $\geq 5$ & $3.7 \%$ & $0.50(0.20-1.29)$ & 0.15 & & \\
\hline
\end{tabular}

*Relative risk using generalized estimating equations with adjustment for repeated measures in the same patient.

${ }^{\dagger}$ Relative risk using generalized estimating equations with adjustment for repeated measures in the same patient, age and gender.

reduction in peripheral parasitaemia followed by the longer-acting partner drug eliminating any remaining parasites [17]. ACT has now become one of the most effective tools for malaria control and the emergence of resistance to the artemisinin class of anti-malarial drugs would pose a major global health problem. Artemisinin resistance was first reported in Western Cambodia and has now emerged or spread to other areas of Southeast Asia [3-6]. Currently the only way to identify artemisinin resistance is through the detection of phenotypic trait of delayed parasite clearance in vivo following the initiation of therapy. Thus, there is great interest in surveillance studies of early parasite clearance to provide an "early warning system" for the emergence/spread of artemisinin resistance in areas where this has not be previously documented. However, accurate characterization of the clinical phenotype of delayed parasite clearance may be complicated by a number of factors acting independent of artemisinin resistance, such as drug concentrations, pharmacodynamics properties of the partner drug, pretreatment parasite density, and host immunity.

In this study, a number of factors were independently associated with persistent parasitaemia on days one and two following the initiation of ACT. A higher pretreatment parasite density had the strongest association with persistent parasitaemia on days one and two. This finding is expected given that time to parasite clearance is a function of the baseline parasite density [18]. Thus any assessment of early parasite clearance should account for the pre-treatment parasite density. One method proposed to account for pre-treatment parasite density is to estimate the parasite clearance rate, as defined by the slope of the linear portion of the natural logarithm of the parasite clearance curve, rather than simply the proportion of patients who remain parasitaemic following the initiation of therapy [11]. However, this method requires frequent sampling, ideally every six to eight hours or at least every 12 hours until parasite clearance, which may pose considerable challenges in the setting of routine drug efficacy surveillance studies. For clinical studies that continue to rely on less frequently sampling and determine the proportion of patients who remain parasitaemic at different time points, control of pre-treatment parasite density will be essential for monitoring trends in early parasite clearance over time and space.

In this study a higher pre-treatment temperature was also associated with persistent parasitaemia on days one and two. This finding has been reported in another study from Kenya [19] and may be a surrogate marker of a less effective host immune response. In addition, infection with HIV was associated with persistent parasitaemia on day two in this study, providing further evidence of the 
role of the host immune response on early parasite clearance. HIV infection has been associated with an increased incidence of malaria [20] and increased risk of re-infection following therapy [21]. In a small study from Ethiopian adults, HIV-infected patients had a higher risk of persistent parasitaemia 32 hours after the initiation of artemisinin monotherapy compared to HIV-uninfected patients (six of seven $v s$ two of $12, \mathrm{p}=0.003$ ) [22]. Age has also been used as a surrogate marker of anti-malarial immunity and would be expected to influence early parasite clearance. Although the age range for patients enrolled in this study was too narrow for evaluation, other studies have reported associations between younger age and persistent parasitaemia [12,23]

Although early parasite clearance is predominantly a function of artemisinin activity, different formulations of the artemisinin component and partner drugs used in various ACT may also influence early parasite clearance. In this study, treatment with $\mathrm{AL}$ was associated with a higher risk of persistent parasitaemia on day one compared to treatment with DP. This finding appears to have some clinical significance as persistent fever on day one was also higher in patients treated with AL compared to DP. Similar findings of a higher risk of persistent parasitaemia on day one in AL compared to DP have also been reported in a study from Kenya [19] as well as a large meta-analysis of studies from Asia and Africa [12].

There were several limitations to this study. As mentioned earlier, blood smear samples were obtained once daily, therefore, it was not possible to accurately estimate the parasite clearance rate as a continuous variable. This study also included patients across a narrow age range (47-60 months) and over a relatively short period of calendar time, thus it was not possible to evaluate age as a potential risk factor or temporal trends in early parasite clearance. Finally, only DP was fully administered as directly observed therapy, as it was given once daily when a child presented to the study clinic. In contrast, AL was given twice daily and only one of the two daily doses was directly observed. If the second dose of $\mathrm{AL}$ was not appropriately administered at home, differences in parasite clearance between AL and DP may have been overestimated.

In summary, results from this study provide reassuring evidence that among children living in an area of high malaria endemicity in Uganda, parasite clearance following treatment with AL and DP was excellent. To provide a "baseline" assessment of the dynamics of early parasite clearance in this study population, several factors were associated with persistent parasitaemia at days one and two after the initiation of therapy, including pre-treatment parasite density, pre-treatment temperature, which ACT was given, and HIV status. In order to accurately detect temporal changes in early parasite clearance associated with the emergence of artemisinin resistance in Africa, analyses should control for these risk factors and potentially others when comparing data across studies. Finally, studies with richer parasite density sampling may be required to model the optimum parasite density sampling approaches (daily, six, eight or 12 hourly) to robustly track changes in early parasite clearance in Africa.

\section{Competing interests}

The authors declare that they have no competing interests.

\section{Authors' contributions}

MKM, AK, MRK, and GD conceived and designed the study. MKM, AK, EO, FO and EA participated in data collection. MKM, AK, MRK, and GD preformed the data analysis. All authors participated in the writing of the manuscript. All authors read and approved the final manuscript.

\section{Acknowledgements}

This research/publication was made possible by Uganda Malaria Clinical Operational and Health Services (COHRE) Training Programme at Makerere University, Grant \#D43-TW00807701A1, from the Fogarty International Center (FIC) at the National Institutes of Health $(\mathrm{NIH})$ its contents are solely the responsibility of the authors and do not necessarily represent the official views of FIC or $\mathrm{NIH}$. We are grateful to all the parents and guardians for kindly giving their consent and to the study participants for their cooperation. We thank all the members of the study team for their tireless effort and excellent work. Funding for the main project was provided by the US President's Emergency Plan for AIDS Relief and by Cooperative Agreement No U62P024421 from the Centers for Disease Control and Prevention (CDC); National Center for HIV, Viral Hepatitis, STD, and TB Prevention (NCHHSTP); and Global AIDS Program (GAP). The funders were not involved with study design, data analysis or manuscript preparation. The contents of the manuscript are solely the responsibility of the authors and do not necessarily represent the official views of the CDC.

\section{Author details}

${ }^{1}$ Infectious Diseases Research Collaboration, Mulago Hospital Campus, PO Box 7475, Kampala, Uganda. ²Department of Medicine, San Francisco General Hospital, University of California, San Francisco, CA, USA. ${ }^{3}$ University of Oxford/ KEMRI/ Wellcome Trust Research Programme, Nairobi, Kenya. ${ }^{4}$ Global AIDS Program, Centers for Disease Control and Prevention, Atlanta, GA, USA. ${ }^{5}$ Centers for Disease Control and Prevention, Kampala, Uganda. ${ }^{6}$ Department of Medicine, Makerere University College of Health Sciences, Kampala, Uganda.

Received: 10 September 2013 Accepted: 21 January 2014

Published: 28 January 2014

\section{References}

1. WHO: Guidelines for the treatment of malaria. Secondth edition. Geneva, Switzerland: World Health Organization; 2010.

2. WHO: World Malaria Report 2011. Geneva, Switzerland: World Health Organization; 2011

3. Bethell D, Se Y, Lon C, Tyner S, Saunders D, Sriwichai S, Darapiseth S, Teja-Isavadharm P, Khemawoot P, Schaecher K: Artesunate dose escalation for the treatment of uncomplicated malaria in a region of reported artemisinin resistance: a randomized clinical trial. PLoS One 2011, 6:e19283.

4. Dondorp AM, Nosten F, Yi P, Das D, Phyo AP, Tarning J, Lwin KM, Ariey F, Hanpithakpong W, Lee SJ: Artemisinin resistance in Plasmodium falciparum malaria. N Engl J Med 2009, 361:455-467.

5. Noedl H, Se Y, Sriwichai S, Schaecher K, Teja-Isavadharm P, Smith B, Rutvisuttinunt W, Bethell D, Surasri S, Fukuda MM: Artemisinin resistance in Cambodia: a clinical trial designed to address an emerging problem in Southeast Asia. Clin Infect Dis 2010, 51:e82-e89.

6. Phyo AP, Nkhoma S, Stepniewska K, Ashley EA, Nair S, McGready R, ler Moo C Al-Saai S, Dondorp AM, Lwin KM: Emergence of artemisinin-resistant malaria on the western border of Thailand: a longitudinal study. Lancet 2012, 379:1960-1966. 
7. Ariey $F$, Fandeur $T$, Durand $R$, Randrianarivelojosia $M$, Jambou $R$, Legrand $E$, Ekala MT, Bouchier C, Cojean S, Duchemin JB: Invasion of Africa by a single pfcrt allele of South East Asian type. Malar J 2006, 5:34.

8. Mita T, Venkatesan M, Ohashi J, Culleton R, Takahashi N, Tsukahara T, Ndounga M, Dysoley L, Endo H, Hombhanje F: Limited geographical origin and global spread of sulfadoxine-resistant dhps alleles in Plasmodium falciparum populations. J Infect Dis 2011, 204:1980-1988.

9. Roper C, Pearce R, Nair S, Sharp B, Nosten F, Anderson T: Intercontinental spread of pyrimethamine-resistant malaria. Science 2004, 305:1124.

10. Fairhurst RM, Nayyar GM, Breman JG, Hallett R, Vennerstrom JL, Duong S, Ringwald P, Wellems TE, Plowe CV, Dondorp AM: Artemisinin-resistant malaria: research challenges, opportunities, and public health implications. Am J Trop Med Hyg 2012, 87:231-241.

11. Flegg JA, Guerin PJ, White NJ, Stepniewska K: Standardizing the measurement of parasite clearance in falciparum malaria: the parasite clearance estimator. Malar J 2011, 10:339.

12. Das D, Price RN, Bethell D, Guerin PJ, Stepniewska K: Early parasitological response following artemisinin-containing regimens: a critical review of the literature. Malar J 2013, 12:125.

13. Stepniewska K, Ashley E, Lee SJ, Anstey N, Barnes KI, Binh TQ, D'Alessandro U, Day NP, de Vries PJ, Dorsey G: In vivo parasitological measures of artemisinin susceptibility. J Infect Dis 2010, 201:570-579.

14. Okello PE, Van Bortel W, Byaruhanga AM, Correwyn A, Roelants P, Talisuna A, D'Alessandro U, Coosemans M: Variation in malaria transmission intensity in seven sites throughout Uganda. Am J Trop Med Hyg 2006, 75:219-225.

15. Arinaitwe E, Sandison TG, Wanzira H, Kakuru A, Homsy J, Kalamya J, Kamya MR, Vora N, Greenhouse B, Rosenthal PJ, Tappero J, Dorsey G: Artemether-lumefantrine versus dihydroartemisinin-piperaquine for falciparum malaria: a longitudinal, randomized trial in young Ugandan children. Clin Infect Dis 2009, 49:1629-1637.

16. Sandison TG, Homsy J, Arinaitwe E, Wanzira H, Kakuru A, Bigira V, Kalamya J, Vora N, Kublin J, Kamya MR, Dorsey G, Tappero JW: Protective efficacy of co-trimoxazole prophylaxis against malaria in HIV exposed children in rural Uganda: a randomised clinical trial. BMJ 2011, 342:d1617.

17. White N: Antimalarial drug resistance and combination chemotherapy. Philos Trans R Soc Lond B Biol Sci 1999, 354:739-749.

18. White $\mathrm{NJ}$ : Assessment of the pharmacodynamic properties of antimalarial drugs in vivo. Antimicrob Agents Chemother 1997, 41:1413-1422.

19. Borrmann S, Sasi P, Mwai L, Bashraheil M, Abdallah A, Muriithi S, Fruhauf $H$, Schaub B, Pfeil J, Peshu J, Hanpithakpong W, Rippert A, Juma E, Tsofa B, Mosobo M, Lowe B, Osier F, Fegan G, Lindegårdh N, Nzila A, Peshu N, Mackinnon M, Marsh K: Declining responsiveness of Plasmodium falciparum infections to artemisinin-based combination treatments on the Kenyan coast. PLoS One 2011, 6:e26005.

20. Whitworth J, Morgan D, Quigley M, Smith A, Mayanja B, Eotu H, Omoding $\mathrm{N}$, Okongo M, Malamba S, Ojwiya A: Effect of HIV-1 and increasing immunosuppression on malaria parasitaemia and clinical episodes in adults in rural Uganda: a cohort study. Lancet 2000, 356:1051-1056.

21. Kamya MR, Gasasira AF, Yeka A, Bakyaita N, Nsobya SL, Francis D, Rosenthal PJ, Dorsey G, Havlir D: Effect of HIV-1 infection on antimalarial treatment outcomes in Uganda: a population-based study. J Infect Dis 2006, 193:9-15.

22. Birku Y, Mekonnen E, Bjorkman A, Wolday D: Delayed clearance of Plasmodium falciparum in patients with human immunodeficiency virus co-infection treated with artemisinin. Ethiop Med J 2002, 40(Suppl 1):17-26.

23. Lopera-Mesa TM, Doumbia S, Chiang S, Zeituni AE, Konate DS, Doumbouya M, Keita AS, Stepniewska K, Traore K, Diakite SA, Ndiaye D, Sa JM, Anderson JM, Fay MP, Long CA, Diakite M, Fairhurst RM: Plasmodium falciparum clearance rates in response to artesunate in malian children with malaria: effect of acquired immunity. J Infect Dis 2013, 207:1655-1663.

doi:10.1186/1475-2875-13-32

Cite this article as: Muhindo et al:: Early parasite clearance following artemisinin-based combination therapy among Ugandan children with uncomplicated Plasmodium falciparum malaria. Malaria Journal 2014 13:32.

\section{Submit your next manuscript to BioMed Central and take full advantage of:}

- Convenient online submission

- Thorough peer review

- No space constraints or color figure charges

- Immediate publication on acceptance

- Inclusion in PubMed, CAS, Scopus and Google Scholar

- Research which is freely available for redistribution

Submit your manuscript at www.biomedcentral.com/submit
C Biomed Central 